\title{
INFLUENCE OF TECHNICAL TRAINING WITH AN INCREASED SHARE OF NON-DOMINANT LEG EXERCISES ON REDUCTION IN LOWER LIMBS FUNCTIONAL ASYMMETRY IN YOUNG SOCCER PLAYERS
}

original paper

doi: https://doi.org/10.5114/hm.2018.74635

\section{KRZYSZTOF LIPECKI}

Cracow University of Economics, Cracow, Poland

\section{ABSTRACT}

Purpose. The aim of the study was to evaluate the effects of a 6-month technical training program with an increased share of non-dominant leg (NDL) drills on technical skill level and effectiveness of 1v1 playing in young football players.

Methods. The participants were young male soccer players $(n=16 ; 11.6 \pm 0.6$ years; $147.5 \pm 8.8 \mathrm{~cm} ; 37.2 \pm 6.4 \mathrm{~kg})$ from Polish elite soccer academy, training 3 times a week for 90 minutes. They followed a special training program, with 30 minutes of each training session spent on technical drills with the use of a 75/25 movement symmetrization variant: $75 \%$ of technical drills engaged the NDL and 25\% the dominant leg (DL). Before and after the training program, the range of asymmetry was measured for 4 technical skills (dribbling, juggling, short and long passing the ball) and for 1v1 playing (number of goals scored with NDL and DL).

Results. The results revealed a reduction in the asymmetry of the analysed skills by $4.3 \%$. Most tests indicated a decrease at individual stages of examinations (before and after training), with 2 tests, i.e. the short shots performed low to the ground with the DL and the number of goals scored with DL in 1v1 games, showing a statistically significant reduction (by $8.7 \%$ and $24.2 \%$, respectively; $p<0.05$ ).

Conclusions. Technical training with the emphasis on using NDL reduces the asymmetry of technical and tactical skills. However, the time spent on drills by 11-year-old athletes may lead to a decrease in DL skills.

Key words: football, dominant leg, technical skills, small-sided game (1v1)

\section{INTRODUCTION}

A precondition for the achievement of a champion skill level in soccer is to have an adequately high level of technical preparation, with its significant problem being asymmetry in performing technical and tactical elements [1, 2]. Functional advantage of one of the limbs is termed functional asymmetry and manifests itself in a difference in the frequency and accuracy of performing complex movements with the right and left leg [3]. This substantially limits the offensive potential of players, leading to a more effective counteracting of the opponents. Furthermore, it can cause overload, thus increasing the injury risk [4-6]. It should be emphasized that the symmetrical preparation of athletes (ability to play with both legs and performing feints in both directions) is particularly important in the sports where competing with the opponent is direct and of key importance to achieving success $[1,7]$.

The problems of functional asymmetry in technical skills seem to have been relatively well explored in terms of shots on the goal in elite soccer players [8-11]. Studies have demonstrated that the teams with best performance during the most important soccer events (European championship, World Cup) had the highest number of 'symmetrical' players who were able to perform this technical element with both right and left legs, although world-class elite players are characterized by an asymmetry in the frequency of performing shots on the goal (reaching even 96.2\%) [12], whereas their effectiveness for the dominant leg (DL) and nondominant leg (NDL) is similar (87\% and 85\%, respec-

Correspondence address: Krzysztof Lipecki, Faculty of Management, Department of Tourism, Cracow University of Economics, ul. Rakowicka 27, 31-510 Kraków, Poland, e-mail: lipeckik@uek.krakow.pl

Received: December 19, 2017

Acepted for publication: March 13, 2018

Citation: Lipecki K. Influence of technical training with an increased share of non-dominant leg exercises on reduction in lower limbs functional asymmetry in young soccer players. 2017;18(5)special/issue:157-164; doi: https://doi.org/10.5114/ hm.2018.74635. 
tively). Less effort seems to have been devoted to the asymmetry of other technical skills (e.g. ball handling, shooting with the medial part of the foot or with the internal instep) [13-16] and few studies have attempted to determine the asymmetry during the game (smallsided games) $[1,17,18]$. It seems that the level of asymmetry varies depending on a concrete technical ability and reduces as the player reaches the level of a champion. Regardless of age and level of qualification, the lowest range of asymmetry is observed for various types of ball handling (5-15\%), whereas a greater range - for short passes performed low to the ground (with the medial part of the foot or the external instep) (10-30\%). An even greater variation between DL and NDL was noted for playing effectiveness in attack and defence in $1 \mathrm{v} 1$ test games (30-70\%) [18].

The importance of symmetrical preparation for the achievement of sports success encourages coaches, researchers, and other people involved in sport to explore training methods aimed at reducing functional asymmetry of lower limbs in soccer players. In the literature, several authors have evaluated the effectiveness of 3 variants of this type of training, with different share of exercises used to improve DL and NDL. In the part devoted to technical improvement (mostly this was 30-45 minutes of each training) in the first variant, the players used only NDL (100/0, i.e. they spent $100 \%$ of the time for the improvement of the NDL) [1, 17, 19-21]. In the second variant, they performed exercises with the proportion of $75 / 25$ to the benefit of the NDL (75\% NDL, 25\% DL) [2, 22]. In the third, the players spent a similar amount of time (50/50) for the improvement of NDL and DL (50\% NDL, 50\% DL) [2]. In the remaining part of training (60 minutes), athletes did not have any restrictions concerning the method (choice) of using lower limbs.

It should be emphasized that most experiments assumed the variant of training in which athletes used exclusively NDL (100/0). It turns out that this type of training is effective in reducing functional asymmetry of lower limbs, evaluated in both isolated technical tests [19, 20] and in small-sided 5v5 games [1, 17]. However, the training was mainly aimed to improve the abilities of NDL. Only Haaland and Hoff [21], who followed the indicated training variant, found the improved effectiveness of DL. Furthermore, Witkowski et al. [2], who applied the 50/50 and 75/25 variants, and Witkowski [22] in the training with $75 / 25$ proportions recorded a reduction in functional asymmetry while improving the skills of both lower limbs. Furthermore, it was found that the $75 / 25$ variant was more effective (greater reduction in asymmetry and improved skills of both NDL and DL). According to these authors, multiple repetition of an exercise with one leg (e.g. NDL) and, for the contrast, periodical performing the movement with the opposite limb (here: DL) is conducive to greater control, 'refreshes' the kinaesthetic sensations, reduces fatigue of the limb, consequently leading to improved technique [2, 23, 24]. In addition, performing the exercises with both NDL and DL leads to learning by one limb from the other (termed interlateral transfer), which is not observed when only one leg is used $[1,17,20]$. It should be emphasized that most studies in this field have evaluated players aged 12 and older (12-20 years of age) [1, 2, 19-22]. Therefore, it seems interesting to examine the effects of such a training program in a group of younger athletes.

The aim of the study was to evaluate the effects of a 6-month technical training program with the advantage of the NDL drills on technical skill level and effectiveness of $1 \mathrm{v} 1$ playing in young football players.

The study attempted to provide the answer to the following questions:

1. Does technical training with the advantage of the use of NDL lead to a reduction in the asymmetry of technical and tactical skills among young soccer players?

2. Do proportions adopted for the technical training $(75 \%$ of time spent on the NDL improvement and $25 \%$ on the DL improvement) lead to adverse effects such as stabilization or a reduction in the DL skills?

\section{MATERIAL AND METHODS}

\section{Participants}

The study participants were young male soccer players $(n=16)$ from Polish elite soccer academy. Their mean age equalled $11.6 \pm 0.6$ years, body height $147.5 \pm 8.8 \mathrm{~cm}$, body mass $37.2 \pm 6.4 \mathrm{~kg}$, and training experience $3.1 \pm 1.1$ years. The players trained 3 times a week for 90 minutes during each training session and played one match every week (60 minutes). A higher proportion of the athletes used the right leg as the DL (87.5\%) compared with the left (12.5\%). All the players volunteered to participate in the study and each participant and their parents provided their written consent. A warm-up routine was applied before the examinations (20 minutes). The players were informed about the aim of the study. 
Evaluation of technical and tactical skills

The DL of each player was determined by the Hoffman method [25] with a kicking task [26]. There was also an assessment by a coach, who assumed the DL was used more frequently during performance of different technical elements associated with the soccer game. Technical and tactical skills were evaluated by means of sport and motor skills tests [27, 28] and observation of sports competition during 1v1 small-sided games [18] in order to diagnose:

1. The speed of ball handling with directional changes: the dribbling the ball between uprights with a change of direction test. The player was asked to dribble the ball on a specified route (slalom between poles) using only one leg (DL or NDL). The player performed 2 tests for each leg and further analysis concerned better result for DL and NDL.

2. The accuracy of short shots (passes) performed with the central instep from the air: the juggling alternately with the foot and the head test. The number of foot-head cycles performed by a player within $30 \mathrm{sec}-$ onds with only one leg was determined. The better result of the 2 tests was written separately for DL and NDL.

3. The effectiveness of short shots (passes) low to the ground with the medial part of the foot: the passes to a target performed low to the ground with the medial part of the foot test. The number of goals (points) scored by the player using the shots performed low to the ground with the medial part of the foot from the distance of $6 \mathrm{~m}$ in 90 seconds was determined; further analysis concerned better results from the 2 tests, separately for the DL and NDL.

4. The effectiveness of long shots (passes) with the internal instep from the ground: the long passes to a target with the internal instep from the ground test. After an approach run, the player performed 20 shots (10 with DL and 10 with NDL, alternately) from the ground using the internal instep to the goal. The goal $(3 \times 2 \mathrm{~m})$ was divided into 2 parts with a tape $(1 \mathrm{~m}$ from the ground) and the player scored 3 points if the ball went on target (the upper part) and 1 point when it went to the lower part. Scores were not counted if the ball bounced from the ground before reaching the goal. The result was represented by the total points scored from 10 shots, separately for DL and NDL.

5. The effectiveness of $1 \mathrm{v} 1$ playing in attack: the $1 v 1$ playing to two goals without a goalkeeper test. In a specified playing field $(20 \times 20 \mathrm{~m}$ square divided into 2 halves, $1.5 \times 1 \mathrm{~m}$ goal), two players competed with each other (1v1) to score as many goals as possible and lose fewest possible goals. Goals were counted only if they were scored from the opponent's half. The roundrobin tournament was applied. Each match was 2 minutes long $(2 \times 1$ minute with changing ends), and the next competition could occur only after a $5-8$-minute rest. The number of goals scored with DL and NDL was recorded after each match. The effectiveness of a player in attack was represented by the number of goals scored in all matches. The test reliability was $r=0.83$ at $p<0.05$.

\section{Experimental design}

The aim of the variant of technical training employed in the study was to reduce the asymmetry in the level of technical and tactical preparation of the young players. The players used the $75 / 25$ symmetrization variant for technical improvement drills for 30 minutes during each training session, i.e. $75 \%$ of the time was spent on the improvement of technical elements performed with NDL and 25\% for those performed with DL. In the remaining part of training (60 minutes), the players did not have any restrictions or coercion in using lower limbs. The drills oriented at equalization of the abilities between both legs were performed 3 times a week for 6 months. There were therefore 72 training sessions, with the total duration of drills of 2160 minutes (36 hours). Both before the training program and after its completion, the range of asymmetry was measured for 4 technical skills (dribbling, juggling, short and long passing the ball) and for 1v1 playing (number of goals scored with NDL and DL).

\section{Statistical analysis}

The STATISTICA 12 PL (for Windows) software was used for the statistical analysis of the data. The basic quantitative characteristics were determined for the variables measured: arithmetic means, standard deviations $(S D)$, and indices of skewness, kurtosis and variability. Before evaluating the statistical significance of the differences, the authors verified consistency of the variables distribution with normal distribution by means of the Shapiro-Wilk W test. The repeated measures ANOVA for leg (DL vs. NDL) and test (before vs. after) was used to compare the changes in the results. To assess the significance of differences between the DL and NDL efficiency in each of the measurements and for individual legs in subsequent measurements, the post-hoc LSD Fisher test was used. The results at the level of $p<0.05$ were considered 


\section{HUMAN MOVEMENT}

K. Lipecki, Non-dominant leg technical training

statistically significant. Percentage differences were also analysed between the values of the variables obtained in both examinations (before and after the training program) and between DL and NDL.

\section{Ethical approval}

The research related to human use has been complied with all the relevant national regulations and institutional policies, has followed the tenets of the Declaration of Helsinki, and has been approved by the authors' institutional review board or an equivalent committee.

\section{RESULTS}

The results of the dribbling the ball between uprights with a change of direction for both legs from the period between the pre-test and post-test are presented in the form of means and $S D$ in Figure 1. No significant changes in DL or NDL were found, whereas significant differences occurred between DL and NDL, both before the test $(p<0.001)$ and after it $(p<0.001)$. Asymmetry between the pre-test (13.6\%) and post-test $(12.0 \%)$ examination by $1.6 \%(F=0.18 ; p=0.678)$ was reduced insignificantly.

No significant changes between the pre-test and posttest examination in DL or NDL abilities were found in the juggling alternately with the foot and the head test. Significant differences were observed between DL and NDL both before the test $(p=0.011)$ and after it $(p=$ 0.007 ), whereas asymmetry increased by $3.0 \%$ yet statistically insignificantly $(F=0.04 ; p=0.840)$ (Figure 2).

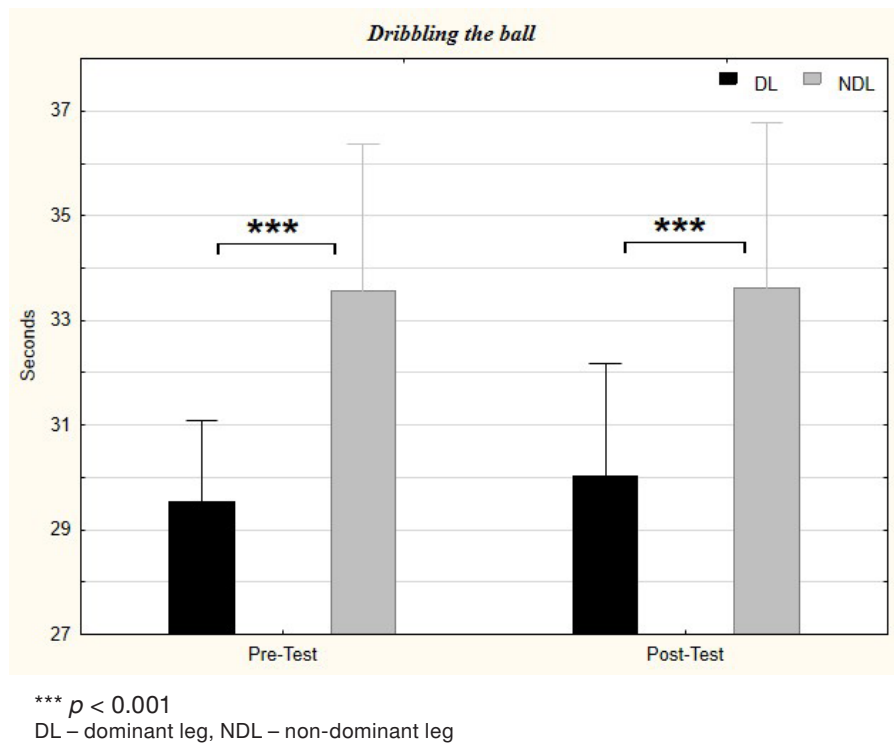

Figure 1. Changes in the results between pre-test and post-test examination for both legs in the dribbling test
In the passes to a target performed low to the ground with the medial part of the foot test, the DL ability was significantly deteriorated between the pre-test and post-test examination by $8.7 \%$ ( $p=0.033$ ), whereas the NDL ability was insignificantly improved by $5.4 \%$ ( $p=$ 0.482 ). Differences between DL and NDL in the pretest $(p<0.001)$ and post-test $(p=0.013)$ examination were statistically significant. Range of symmetry was significantly reduced by $10.3 \%$ between the pre-test and post test examination $(F=4.36 ; p=0.046)$ (Figure 3).

In the long passes to a target with the internal instep from the ground test, no significant changes be-

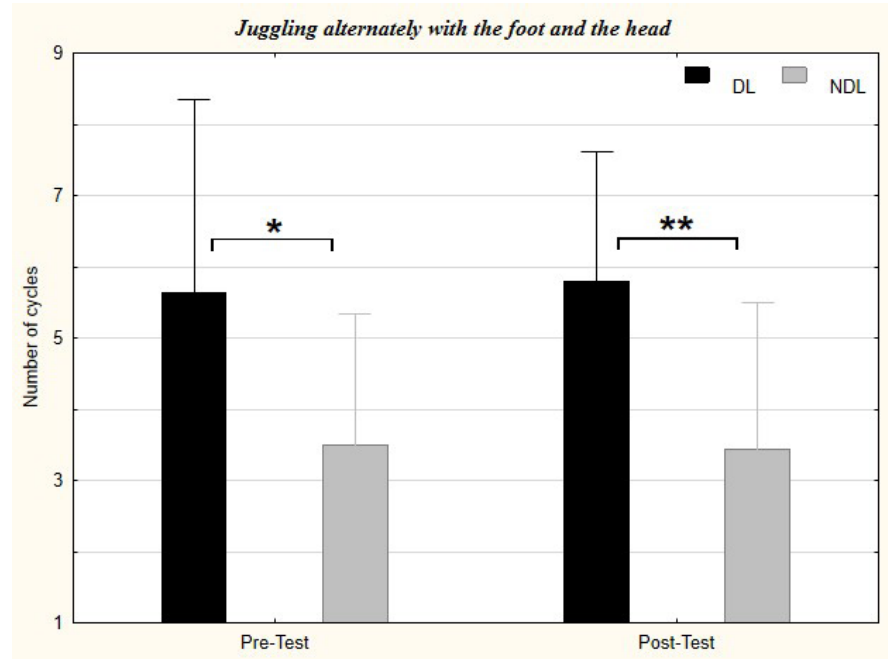

* $p<0.05, " p<0.01$

$\mathrm{DL}$ - dominant leg, NDL - non-dominant leg

Figure 2. Changes in the results between pre-test and post-test examination for both legs in the juggling test

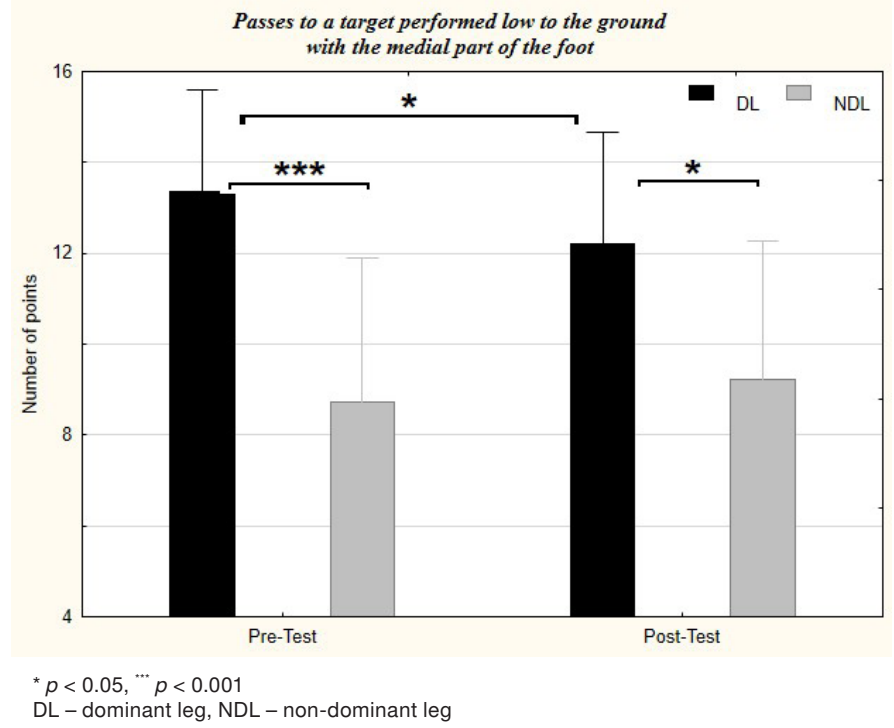

Figure 3. Changes in the results between pre-test and post-test examination for both legs in the passes to a target test 
tween the pre-test and post-test examination were found for either leg, whereas significant differences between DL and NDL were observed both before the test ( $p<$ $0.001)$ and after it $(p<0.001)$. Asymmetry was reduced between the pre-test and post-test examination by $0.6 \%$ $(F=0.03 ; p=0.878)$ (Figure 4).

In the $1 v 1$ playing to two goals without a goalkeeper test, a significant reduction was documented between the pre-test and post-test examination in the number of goals scored with DL by $24.2 \%$ ( $p=0.048$ ), whereas an insignificant reduction was found for NDL by $8.4 \%$ ( $p=0.507)$. Differences between DL and NDL before

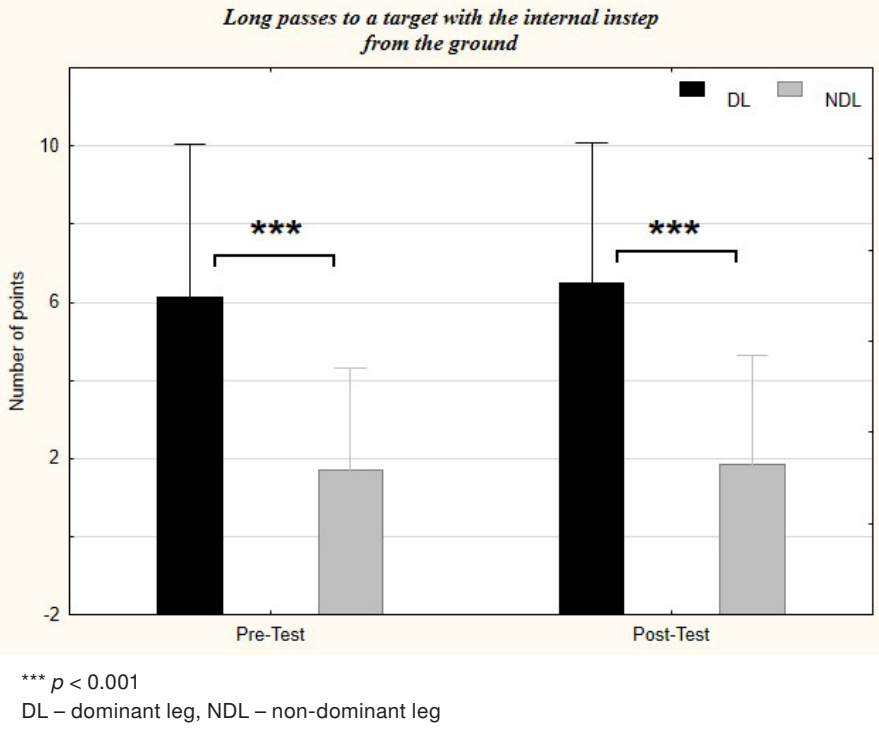

Figure 4. Changes in the results between pre-test and post-test examination for both legs in the long passes test

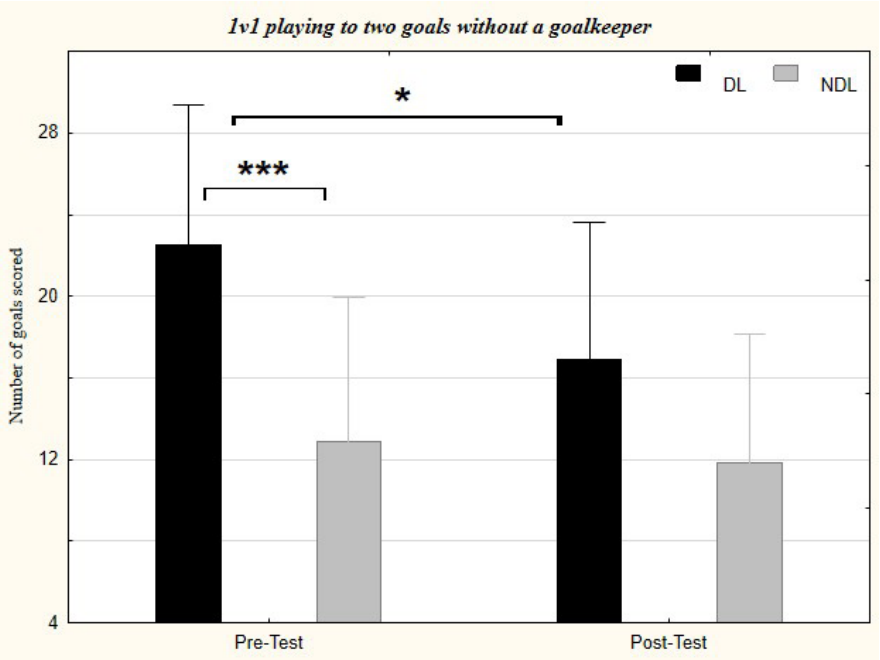

${ }^{*} p<0.05, \cdots p<0.001$

$\mathrm{DL}$ - dominant leg, NDL - non-dominant leg

Figure 5. Changes in the results between pre-test and post-test examination for both legs in the $1 v 1$ playing test the test were $41.8 \%$ and turned out to be significant $(p=0.002)$, whereas after the test, they equalled $29.8 \%$ and were statistically insignificant $(p=0.084)$. The range of asymmetry between the pre-test and posttest examination was reduced by $12.0 \%$. However, this change was statistically insignificant $(F=2.51$; $p=0.128$ ) (Figure 5).

The results revealed that both before the beginning of the program and after its completion, differences between DL and NDL performance in all tests (except for the number of goals scored during $1 \mathrm{v} 1$ playing with NDL) were statistically significant $(p<0.05)$. Furthermore, after 6 months of exercises, we documented a reduction in asymmetry in 4 (ball handling, passing with the medial part of the foot low to the ground, long passes with the internal instep, and 1v1 playing) of the 5 analysed tests, with statistically significant differences found for short ball passes $(p>0.05)$. With regard to the differences between the DL and NDL in total from all the tests, a reduction in asymmetry by $4.3 \%$ was observed between the pre-test $(40.1 \%)$ and post-test $(35.7 \%)$ results.

The analysis of changes in the level of indices of technical and tactical skills at consecutive stages of the examinations (before and after training) revealed insignificant improvements in the results of 4 of 10 tests $(p>0.05)$. In the other 6 tests, the results were decreased, of which in the passes to a target performed low to the ground with the medial part of the foot with the DL and the $1 v 1$ playing to two goals without a goalkeeper with the DL tests, the reduction was statistically significant $(p<0.05)$.

\section{DISCUSSION}

The study aimed to evaluate the degree to which technical training with an increased share of the NDL contributed to the reduction in the asymmetry regarding technical and tactical skills in young soccer players. The significant reduction of asymmetry in short shots (passes) and reduction in the total level of asymmetry in all the evaluated skills (by $4.8 \%$ ) suggests the effectiveness of the applied variant of movement symmetrization in the group of 11-year-old soccer players. A similar training program followed by younger athletes (mean age, $9.5 \pm 1.0$ years) also led to a reduction in functional asymmetry (number and effectiveness of technical actions with the ball) observed during the game (5v5 small-sided game) [17]. Technical training with an increased share of NDL resulted in even bigger effects in older players (aged over 18 years). In players aged 13 years, the analogous symmetriza- 
tion variant $(75 \%$ of time spent on the NDL improvement and 25\% time spent on the DL improvement) produced a reduction in asymmetry by $7.9 \%$ in elite players [2] and by $24.6 \%$ in less skilled players [22], whereas training focused exclusively on the NDL caused a 5.0\% decrease in players aged 12-14 years [19, 20] and by $15.0 \%$ in those aged $15-20$ years [21].

Furthermore, our study showed that regardless of the training program used, the differences between the NDL and DL were statistically significant in all tests $(p<0.05)$. This indicates substantial reserves concerning a symmetrical performance of technical and tactical elements in players aged 11 years. The finding is consistent with other research $[14,18]$.

The study also analysed changes in the results of technical tests and 1v1 playing achieved by young players after 6 months of training. The lack of statistically significant results and stabilization or deterioration observed in most cases may suggest some limitations in the effectiveness of the applied variant of symmetrization in players at this age. However, it is worth emphasizing that the reduction in the number of goals scored with DL during 1v1 playing results mainly from the improved defensive skills, reflected by the lower total number of goals scored in the first (602) and second (485) examination compared with the reduction in the DL skills. Nevertheless, the effects of identical training were more pronounced in a group of 13-year-old players. A half-a-year program contributed to a significant improvement in 2 (i.e. kicking the ball with the external instep low to the ground with the NDL and ball handling with DL) among 6 of the analysed technical skills, whereas no significant deterioration of the physical fitness was found in either limb [2]. Furthermore, a 3-month training in a group of less professional soccer players led to the improvement in 8 out of 10 analysed tests (5 technical skills were diagnosed), and the adopted proportions of exercises did not lead to the negative effects in the form of stabilization or deterioration of DL performance [22].

A lower reduction in asymmetry and the number of tests revealing improved results suggest lower effectiveness of the applied symmetrization variant (75\% NDL and 25\% DL) in the group of players aged 11 years compared with older athletes [2, 19-22]. The limited training effects may have been caused by an insufficient level of basic technical skills in younger players. It is recommended for the symmetrization methodology that a new technical element should be first mastered for DL and next learnt with NDL (in the less convenient direction) [29, 30]. Therefore, fur- ther research is needed to evaluate the effectiveness of such training in a group of athletes under 12 years of age.

The examination pointed to certain effectiveness of the program employed for the reduction of functional asymmetry of lower limbs. However, with the absence of a control group, it is difficult to conclude to what extent the observed changes are the effect of the exercise program, the disturbing factors (connected with biological development), or the learning effect during the tests performance. An additional limitation was a relatively short time for the improvement of the NDL in each training (30 minutes) compared with the part without restriction (60 minutes), in which the athletes used mainly the DL. It should be also emphasized that all the participants were male and, consequently, the findings cannot be extended for female players since it has not been verified to date whether sex determines the effectiveness of such training. The results should be interpreted especially with reference to this sample and are characteristic of male elite soccer players aged 11 years.

\section{CONCLUSIONS}

Technical training with the emphasis on the NDL in a group of 11-year-old soccer players leads to reducing the asymmetry of technical and tactical skills, whereas the adopted proportions ( $75 \%$ of time spent on the NDL improvement and $25 \%$ for the DL) can result in the stabilization or reduction of skills observed for the DL.

\section{Acknowledgements}

The study was funded with the resources allocated by the Polish Ministry of Science and Higher Education for the Faculty of Management of the Cracow University of Economics, Poland, to support research conducted by young researchers.

\section{Disclosure statement}

The author has no financial interest or received any financial benefit from this research.

\section{Conflict of interest}

The author states no conflict of interest.

\section{References}

1. Guilherme J, Garganta J, Graça A, Seabra A. Influence of non-preferred foot technical training in reducing lower limbs functional asymmetry among young football players. J Sports Sci. 2015;33(17):1790-1798; doi: 10.1080/02640414.2015.1012100. 
2. Witkowski Z, Lyakh V, Gutnik B, Lipecki K, Rutowicz B, Penchev B, et al. Corrective effects of different training options on development and maturation of professional motor skills from dominant and non-dominant legs of young soccer players. J Phys Educ Sport. 2011;11(3): 291-299.

3. Antosiak-Cyrak K, Podciechowska K, Jajor J, Rostkowska E. Functional asymmetry of the lower limbs in young soccer players. Trends Sport Sci. 2015;22(4): 207-215.

4. Carvalho A, Brown S, Abade E. Evaluating injury risk in first and second league professional Portuguese soccer: muscular strength and asymmetry. J Hum Kinet. 2016;51:19-26; doi: 10.1515/hukin-2015-0166.

5. Croisier JL, Ganteaume S, Binet J, Genty M, Ferret JM. Strength imbalances and prevention of hamstring injury in professional soccer players: a prospective study. Am J Sports Med. 2008;36(8):1469-1475; doi: 10.1177/ 0363546508316764.

6. Liu H, Garrett WE, Moorman CT, Yu B. Injury rate, mechanism, and risk factors of hamstring strain injuries in sports: a review of the literature. J Sport Health Sci. 2012;1(2):92-101; doi: 10.1016/j.jshs.2012.07.003.

7. Owen A, Twist C, Ford P. Small-sided games: the physiological and technical effect of altering pitch size and player numbers. OR Insight. 2004;7(2):50-53.

8. Bergier J, Buraczewski T. Symmetry of shots as an indication of coordinating abilities at World Cup in female football U-19. In: Sadowski J (ed.), Coordination motor abilities in scientific research. Biała Podlaska: Józef Piłsudski Academy of Physical Education in Warsaw, Faculty of Physical Education in Biała Podlaska; 2005; 150-156.

9. Starosta W, Bergier J, Soroka A. Lateral differentiation of executed shots at the goal in female soccer players of European and World Championships. Pol J Sport Tourism. 2010;17(1):25-30.

10. Bergier J, Niewolna N. Technical training for shooting goals for one-side oriented players in the UEFA Women's Euro 2009 [in Polish]. Antropomotoryka. 2012;22(60): 143-152.

11. Bjelica D, Popović S, Petković J. Comparison of instep kicking between preferred and non-preferred leg in young football players. Monten J Sports Sci Med. 2013;2(1): $5-10$.

12. Carey DP, Smith G, Smith DT, Shepherd JW, Skriver J, Ord L, et al. Footedness in world soccer: an analysis of France '98. J Sport Sci. 2001;19(11):855-864; doi: 10.1080/026404101753113804.

13. Witkowski Z, Liakh V, Lipecki K. Indices of special technical and coordination preparation of soccer players aged 13 years in the aspect of movement symmetry [in Polish]. In: Żak S, Spieszny M, Klocek T (eds.), Team games in physical education and sport [in Polish]. Kraków: AWF; Studia i Monografie 33; 2005; 123-127.

14. Lipecki K, Rutowicz B, Witkowski Z. Evaluation of kinaesthetic differentiation in soccer players at various stages of sports experience in light of movement symmetry-asymmetry [in Polish]. In: Żak S, Klocek T (eds.), Recruitment, selection and coaching of children and youth in terms of ball games [in Polish]. Wrocław: Międzynarodowe Towarzystwo Naukowe Gier Sportowych; 2007; 60-64.

15. Teixeira LA, Chaves CEO, Silva MVM, Carvalho MA. Lateral asymmetries in the performance of motor skills related to soccer [in Portuguese]. Kinesis. 1998;20:7792; doi: 10.5902/231654648150.

16. Teixeira LA, Silva MVM, Carvalho MA. Differential practice and lateral asymmetries in motor task related to soccer. J Sport Exerc Psychol. 2001;23(2):78-79.

17. Guilherme J, Garganta J, Graça A, Seabra A. Effect of technical training in functional asymmetry of lower limbs in young soccer players. Rev Bras Cineantropom Desempenho Hum. 2015;17(2):125-135; doi: 10.5007/1980-0037.2015v17n2p125.

18. Witkowski Z. Symmetry and asymmetry of movement in technical and tactical as well as speed and strength preparation of soccer players [in Polish]. Kraków: AWF; 2013.

19. Gür E, Filiz K, Aydos L, Müniroğlu S. Effects of training on skill in non-dominant legs of young soccer players [in Turkish]. e-Journal of New World Sciences Academy. 2008;3(3):116-129.

20. Teixeira LA, Silva MVM, Carvalho MA. Reduction of lateral asymmetries in dribbling: the role of bilateral practice.Laterality. 2003;8(1):53-65; doi:10.1080/713754469.

21. Haaland E, Hoff J. Non-dominant leg training improves the bilateral motor performance of soccer players. Scand J Med Sci Sports. 2003;13(3):179-184; doi: 10.1034/j.1600-0838.2003.00296.x.

22. Witkowski Z. Effect of special training with the emphasis on movement symmetrization on the level of symmetry and asymmetry in technical preparation of young soccer players [in Polish]. In: Żak S, Klocek T (eds.), Recruitment, selection and coaching of children and youth in terms of ball games [in Polish]. Wrocław: Międzynarodowe Towarzystwo Naukowe Gier Sportowych; 2007; 113-119.

23. Starosta W. Kinaesthesia - a new method to improve highest quality movements [in Polish]. Warszawa: Międzynarodowe Stowarzyszenie Motoryki Sportowej; 2015.

24. Starosta W. Interdisciplinary determinants of sports training for children and youth [in Polish]. Warszawa: Międzynarodowe Stowarzyszenie Motoryki Sportowej; 2012.

25. Hoffman M, Schrader J, Applegate T, Koceja D. Unilateral postural control of the functionally dominant and nondominant extremities of healthy subjects. J Athl Train. 1998;33(4):319-322.

26. Parkin S, Nowicky AV, Rutherford OM, McGregor AH. Do oarsmen have asymmetries in the strength of their back and leg muscles? J Sports Sci. 2001;19(7):521-526; doi: 10.1080/026404101750238971. 


\section{HUMAN MOVEMENT}

K. Lipecki, Non-dominant leg technical training

27. Witkowski Z, Ljach W. Tests for evaluation of special technical and coordination preparation of soccer players in the aspect of movement symmetry (part 1) [in Polish]. Trener. 2006;2:5-9.

28. Witkowski Z, Ljach W. Tests for evaluation of special technical and coordination preparation of soccer players in the aspect of movement symmetry (part 2) [in Polish]. Trener. 2006;3:15-19.

29. Starosta W. Movement symmetrization: a new method to develop motor coordination and improve technical skills in beginners and advanced players [in Polish]. Roczniki Naukowe Wyższej Szkoły Wychowania Fizycznego i Turystyki w Białymstoku. 2010;6:25-31.

30. Starosta W. Movements symmetrization - a new concept of motor learning in sport. J Hum Kinet. 1999;1:139-147. 